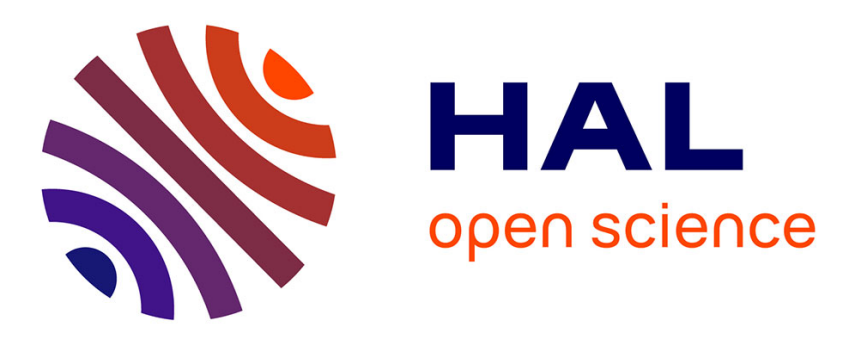

\title{
Compaction behaviour of dry granulated binary mixtures
}

Lucia Perez-Gandarillas, Alon Mazor, David Souriou, Olivier Lecoq, Abderrahim Michrafy

\section{- To cite this version:}

Lucia Perez-Gandarillas, Alon Mazor, David Souriou, Olivier Lecoq, Abderrahim Michrafy. Compaction behaviour of dry granulated binary mixtures. Powder Technology, 2015, 285, pp.62-67. 10.1016/j.powtec.2015.05.003 . hal-01611086

\section{HAL Id: hal-01611086 https://hal.science/hal-01611086}

Submitted on 24 Jul 2018

HAL is a multi-disciplinary open access archive for the deposit and dissemination of scientific research documents, whether they are published or not. The documents may come from teaching and research institutions in France or abroad, or from public or private research centers.
L'archive ouverte pluridisciplinaire HAL, est destinée au dépôt et à la diffusion de documents scientifiques de niveau recherche, publiés ou non, émanant des établissements d'enseignement et de recherche français ou étrangers, des laboratoires publics ou privés. 


\title{
Compaction behaviour of dry granulated binary mixtures
}

\author{
L. Perez-Gandarillas *, A. Mazor, D. Souriou, O. Lecoq, A. Michrafy \\ RAPSODEE (UMR CNRS 2392), Ecole des Mines d'Albi-Carmaux, Campus Jarlard, 81000 Albi, France
}

\section{A B S T R A C T}

Densification process of granules from roll-compacted binary mixtures of microcrystalline cellulose, known as ductile powder, and lactose, considered a brittle material, was investigated using a full-instrumented die press. The role of each component and the effect of the granule size on tablet properties were analysed. Based on the stress transmission measurements in axial and radial directions, the densification behaviour of granules and original mixtures was studied and correlated to the deformation mechanisms of the granules.

Results showed that tablets produced with granules presented lower tensile strength than the tablets produced with the original binary mixtures. Attending the granule size, an increase in the size was translated into a reduction of tensile strength of tablet. The analysis of the axial stress transmission ratio, which measures the loss of stress from the top to the bottom of the powder bed, showed a lower value for granules than for the original mixtures. This difference was attributed to the work consumed in the fragmentation of granules during the densification process. However, the granules fragmentation limits the development of large contact surface between particles and results in lower tablet's strength. Moreover, the reduction of tensile strength was more significant for a high percentage of the ductile material in the mixture. In order to reduce the effect of loss of reworkability, quality by design should be applied from the process development and formulation perspectives.

Keywords:

Roll compaction

Binary mixture

Axial stress

Radial stress

Cellulose

Lactose

\section{Introduction}

In most of the industrial sectors, particulate materials such as metals, fine chemicals, ceramics or pharmaceutical powders have been traditionally processed in order to improve their handling properties. Roll compaction/dry granulation is a process often used to reach that goal whereby the powders are gathered together to form larger particles or agglomerates, achieving an increase in bulk density and an improvement in flowability in order to get uniform tablets [1].

The most challenging limitation of this process is the 'loss of reworkability' or 'loss of tabletability', which leads to an inferior tensile strength of tablets compared with direct compression. Some studies have specifically reported this effect of loss of tabletability on the compression behaviour. It was first attributed to work hardening by Malkowska and Khan [2]. The results showed that the reduction of tensile strength was more significant when the powders were roll compacted at high pressure. The authors concluded that this first compression step limited the binding potential of granules.

Furthermore, the loss in compactability is more significant for plastic materials [3-7]. Plastic materials are more sensitive to roll compaction process due to the consumption of binding potential in the first compression step by modifying properties such as particle size and specific surface area that play an important role in the bonding propensity.

\footnotetext{
Corresponding author.

E-mail address: lucia.gandarillas@mines-albi.fr (A. Michrafy).
}

On the other hand, brittle materials show, in general, lower tensile strength than plastic material, and they are more insensitive to granule size enlargement by roll compaction due to the fact that the extensive fracture of brittle granules during compaction minimises the differences in granule size [8].

In the field of the analysis of the compaction behaviour of binary mixtures [9], investigated the densification behaviour of binary mixtures of MCC and lactose from a mechanistic approach. Through an analysis based on wall friction and stress transmission in axial and radial directions, results provided further insight on the impact of the individual components during the process.

The aim of this work was to investigate the compaction behaviour of granules produced by roll compaction from binary mixtures of a plastic and a brittle material (cellulose microcrystalline and lactose, respectively) and to evaluate the effects of mixture proportions and the granule size on the compaction behaviour and tablet's strength. In this paper, for the first time, the loss of reworkability of granules is analysed through the measurement of stress transmission in axial and radial directions.

\section{Materials and methods}

\subsection{Materials}

Most of the pharmaceutical formulations consist of a mixture of powders in order to confer a variety of properties to the final product. In this study, two common pharmaceutical excipients with different 
mechanical behaviour were used: microcrystalline cellulose Avicel ${ }^{\circledR}$ PH-102 (FMC Biopolymer), which shows excellent plastic deformation, and lactose Granulac ${ }^{\circledR} 140$ (Meggle Gmbh), a brittle powder. Scanning electron microscopy images of these excipients are shown in Fig. 1.

Binary mixtures were prepared in a Turbula mixer (Turbula ${ }^{\circledR}$ System Schatz, Switzerland) for $15 \mathrm{~min}$ at $32 \mathrm{rpm}$. Various mass fractions were studied: $25 \%, 50 \%$ and $75 \%$ of MCC. The true densities of single powders and binary mixtures were determined using a Micromeritics Accupyc 1330 helium gas displacement pycnometer (Table 1).

\subsection{Roll compaction/dry granulation}

Experiments were performed using a Komarek ${ }^{\circledR}$ B050PH laboratory press equipped with smooth rolls $(100 \mathrm{~mm}$ diameter and $38 \mathrm{~mm}$ width) and horizontal feed screw. The gap was kept constant at $1.5 \mathrm{~mm}$. The speed of rolls was $3.75 \mathrm{rpm}$ and the screw speed was varied in order to produce ribbons with the same relative density $(0.600 \pm$ 0.007). Resulting ribbons were milled in an oscillating mill (Erweka, AR402) at $60 \mathrm{rpm}$ using a $1.25 \mathrm{~mm}$ sieve. Granules were imaged using a scanning electron microscope (Philips XL30).

\subsection{Particle size distribution}

The particle size distributions of single powders and original binary mixtures were determined by laser diffraction analysis (Mastersizer 3000, Malvern Instruments Ltd., Malvern, United Kingdom) and their median particle size $\left(\mathrm{d}_{\mathrm{v}, 50}\right)$ was recorded (Table 1$)$.

(a)

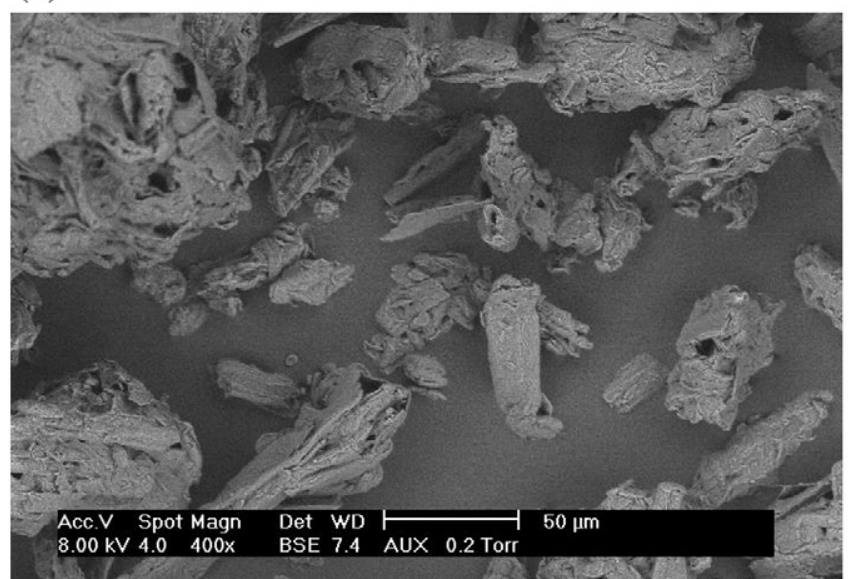

(b)

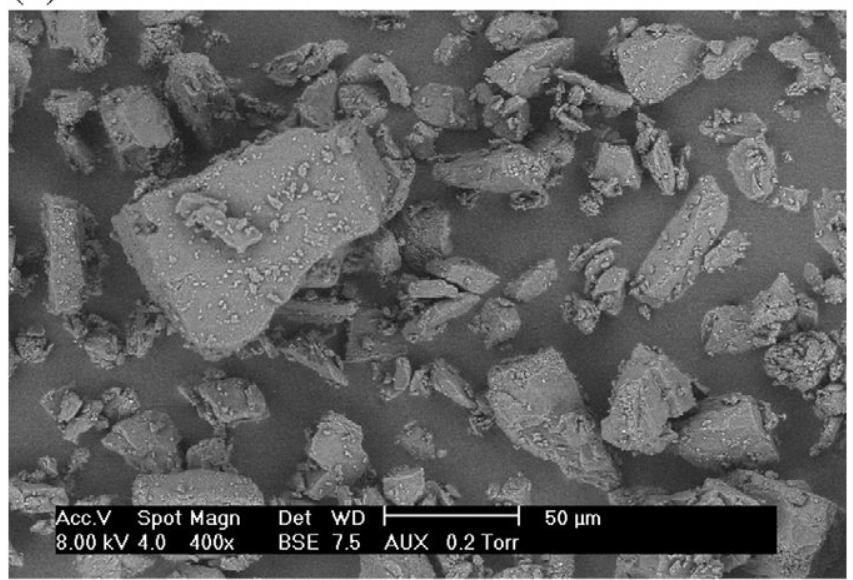

Fig. 1. SEM pictures of (a) MCC102 and (b) lactose Granulac 140.
Table 1

Basic characteristics of single powders and their binary mixtures.

\begin{tabular}{lrl}
\hline Materials & Particle size $\mathrm{d}_{\mathrm{v}, 50}(\mu \mathrm{m})$ & Measured true density $\left(\mathrm{g} / \mathrm{cm}^{3}\right)$ \\
\hline MCC 102 & $129.0 \pm 2.2$ & $1.5717 \pm 0.0006$ \\
Lactose & $59.7 \pm 2.2$ & $1.5391 \pm 0.0003$ \\
75\% MCC/25\% lactose & $104.0 \pm 2.0$ & $1.5614 \pm 0.0022$ \\
50\% MCC/50\% lactose & $92.0 \pm 1.9$ & $1.5563 \pm 0.0019$ \\
25\% MCC/75\% lactose & $76.2 \pm 1.7$ & $1.5537 \pm 0.0002$ \\
\hline
\end{tabular}

For granules, the particle size distribution was determined by sieve analysis (AS 200 digit, Retsch, Germany) at amplitude of 40 for $20 \mathrm{~min}$. The applied sieves were 125, 315, 500, 630, 800, 1000 and $1250 \mu \mathrm{m}$.

\subsection{Compression of tablets}

In order to understand the effect of the particle size and the role of the composition on tablet behaviour, an instrumented press (Frogerais $\mathrm{OA}$ ) was used. The press is equipped with a fixed cylindrical die of $11.28 \mathrm{~mm}$ of diameter and $10 \mathrm{~mm}$ of height. The pressure is applied with the upper punch and the ejection is executed with the lower one.

The press is instrumented with five sensors that allow the measurement of the displacements of the upper and lower punches, the applied axial pressure $\left(\sigma_{\mathrm{u}}\right)$, the transmitted axial pressure to the lower punch $\left(\sigma_{1}\right)$ and the radial stress on the die wall $\left(\sigma_{\mathrm{r}}\right)$. Fig. 2 shows a schematic representation of the die.

Cylindrical flat tablets were prepared by pouring a mass of $0.400 \pm 0.005 \mathrm{~g}$ of material into the die and compacting them at different pressures (from $20 \mathrm{MPa}$ to $140 \mathrm{MPa}$ ). For reproducibility, the mean of three measurements was used for each pressure level. During the compaction process, the pressures and displacements of the upper and lower punches as well as the radial stress on the die were recorded.

The press requires defining the maximum displacement of the upper punch. This maximum displacement corresponds to a certain maximum pressure depending on the material inside the die. For this study, the maximum displacement of the upper punch varied from 6 to $7 \mathrm{~mm}$ in order to get tablets of approximately 3-4 $\mathrm{mm}$ of height at the end of the compaction.

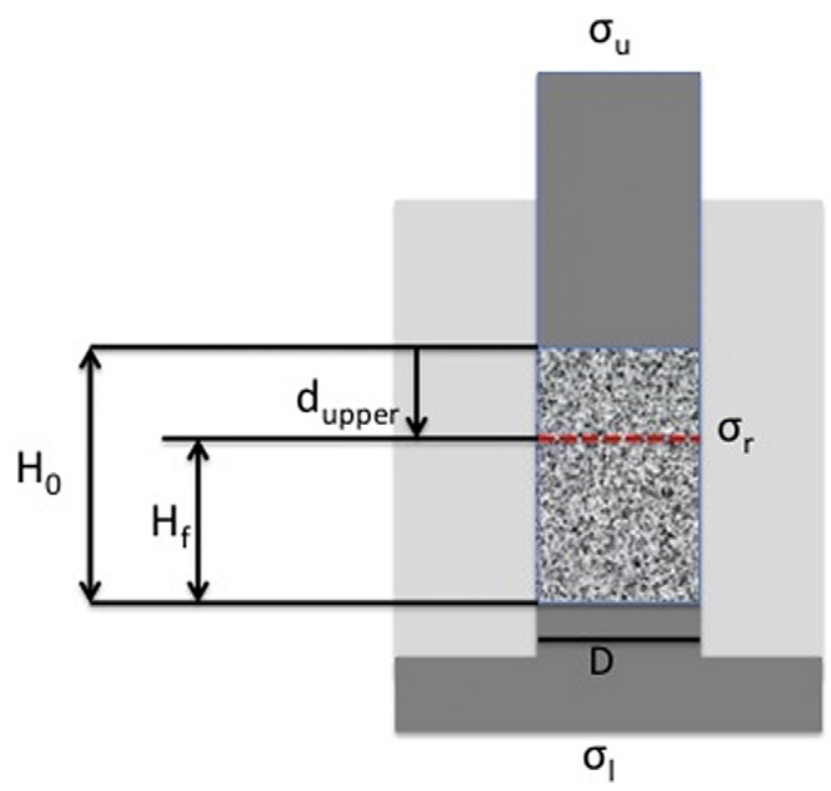

Fig. 2. Scheme of the instrumented die ( $D=$ die diameter, $H_{0}=$ initial height of powder height, $\mathrm{H}_{\mathrm{f}}=$ final height, $\mathrm{d}=$ displacement of upper punch, $\sigma_{\mathrm{u}}=$ upper pressure, $\sigma_{1}=$ lower pressure, $\sigma_{\mathrm{r}}=$ radial pressure). 


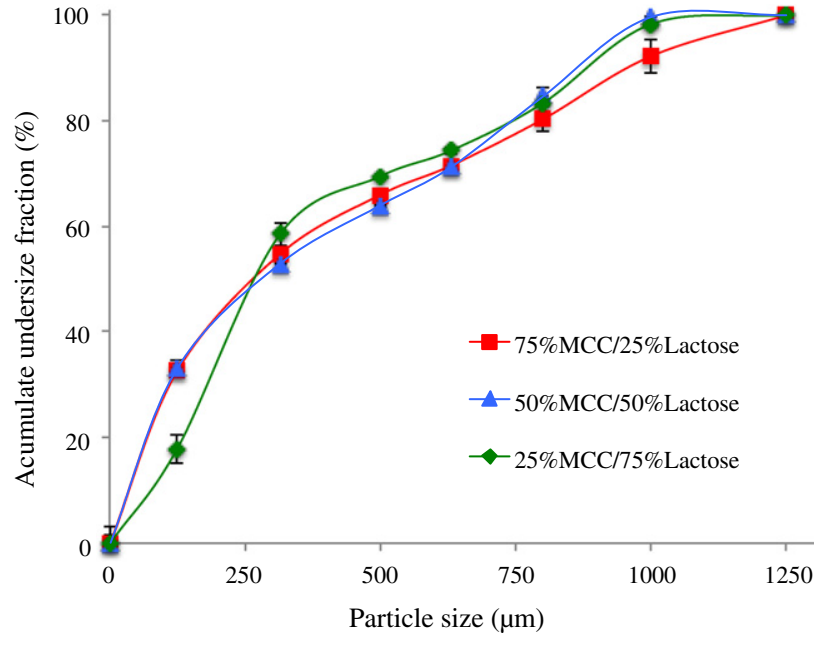

Fig. 3. Particle size distribution of granules.

The ratios of axial and radial stress transmissions, according to the relative density of the tablet, were used as tools to analyse mechanisms of the densification. They allow the quantification of the capacity of the binary mixtures and their granules to convert the applied pressure to the axial and radial directions during the compaction cycle [9]. They were calculated as:

$\operatorname{tr}_{\text {axial }}=\frac{\sigma_{1}}{\sigma_{u}}$

$\operatorname{tr}_{\text {radial }}=\frac{\sigma_{\mathrm{r}}}{\sigma_{\mathrm{u}}}$

\subsection{Tablets characterization}

After ejection, the tablet dimensions (diameter and thickness) were measured with a digital micrometer (Mitutoyo) and tablet mass was weighted with an electronic balance (CP 224S, Sartorius, Germany). These data were used to calculate the relative density (Eq. (3)) of each tablet, where $m$ is the mass, $h$ is the thickness, $D$ is the diameter of the tablet and $\rho_{\mathrm{t}}$ is the true density.

$\rho_{\mathrm{r}}=\frac{4 m}{\pi h D^{2} \rho_{\mathrm{t}}}$

\subsubsection{Compressibility}

The compressibility of a powder bed is the ability to be reduced in volume under pressure. The compressibility of the binary mixtures and their granules was determined applying the Heckel equation [10]. The Heckel equation (Eq. (4)) transforms the force and displacement signals from the compaction cycle to a linear relationship assuming that the process of pore reduction during compression follows firstorder kinetics:

$\ln \left(\frac{1}{1-\rho_{\mathrm{r}}}\right)=\mathrm{K} \cdot \mathrm{P}+\mathrm{A}$

In Eq. (4), $\rho_{\mathrm{r}}$ is the relative density of the compact, $\mathrm{P}$ is the applied pressure, $\mathrm{K}$ is a material-dependent constant known as the Heckel coefficient (related to the plasticity of a compressed powder bed) and $A$ is a constant that expresses the volume reduction before deformation (die filling and powder rearrangement).

\subsubsection{Compactability}

The compactability is defined as the ability of a powder bed to be densified into a compact of a determined strength. The diametrical crushing load of tablets was measured with a diametric strength tester (Erweka TBH30, Erweka ${ }^{\circledR} \mathrm{Gmbh}$, Germany). The tensile strength of the compacts $\left(\sigma_{\mathrm{t}}\right)$ was calculated according to Fell and Newton [11]:

$\sigma_{\mathrm{t}}=\frac{2 \mathrm{~F}}{\pi D h}$

where $\mathrm{F}$ is the load required to break the tablet diametrically. (a)

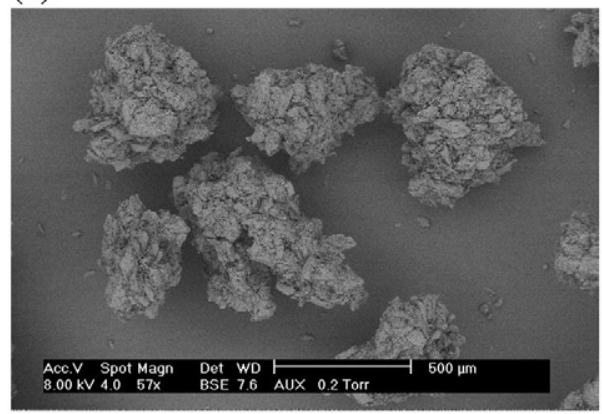

(b)
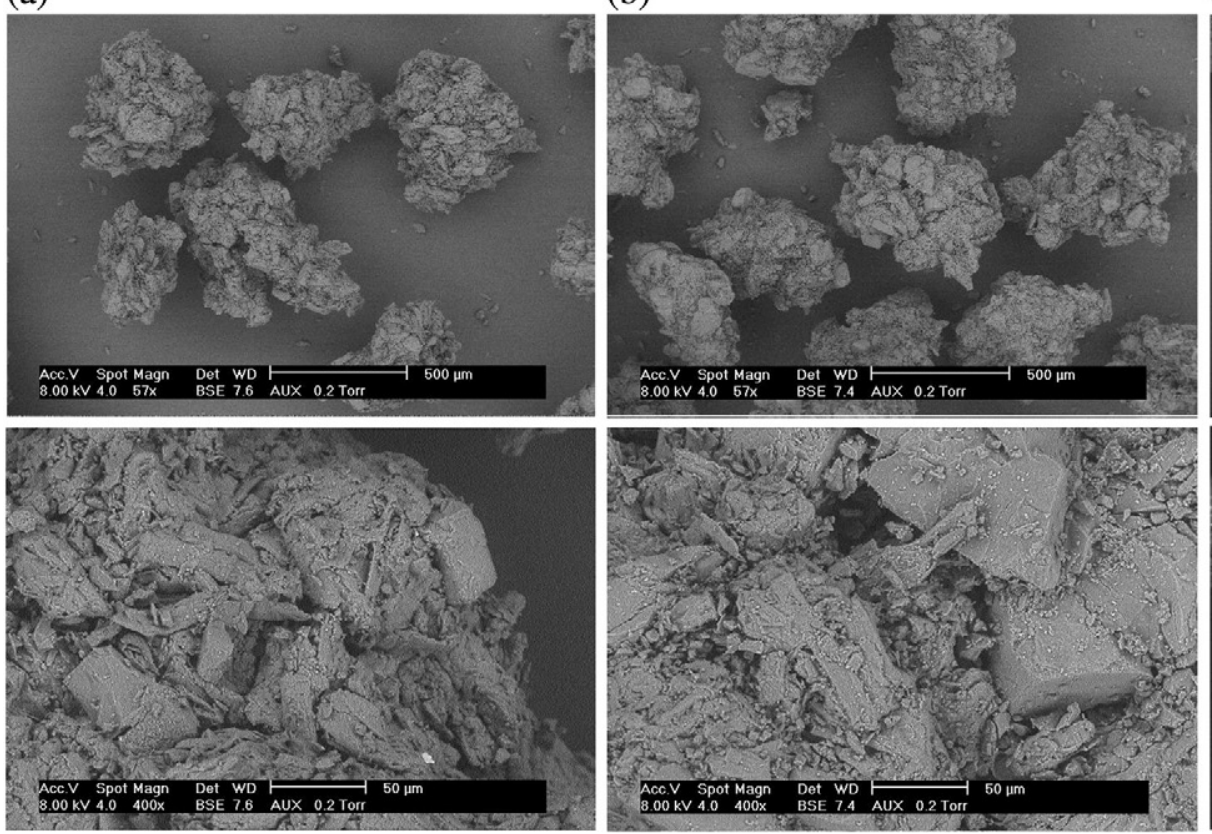

(c)
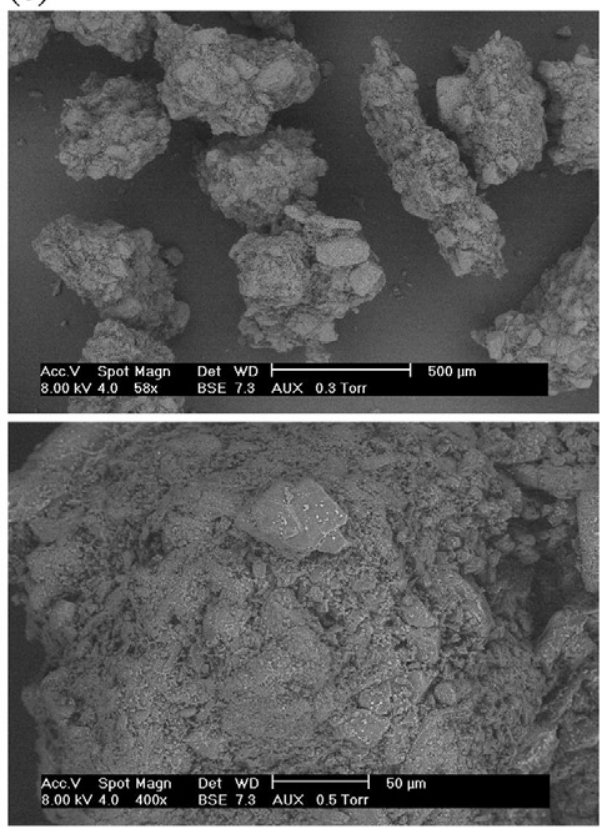

Fig. 4. Scanning electron microscopy images of granules: (a) 75\% MCC/25\% lactose, (b) 50\% MCC/50\% lactose and (c) 25\% MCC/75\% lactose. 
Table 2

Compressibility using Heckel model.

\begin{tabular}{|c|c|c|c|c|}
\hline Mixture & & $\begin{array}{l}\mathrm{K} \times 10^{3} \\
\left(\mathrm{MPa}^{-1}\right)\end{array}$ & $\mathrm{P}_{\mathrm{y}}$ & $\mathrm{R}^{2}$ \\
\hline \multirow[t]{4}{*}{$75 \%$ MCC/25\% lactose } & Non-roll compacted mixture & 7.5 & 133 & 0.969 \\
\hline & Granules $315-500 \mu \mathrm{m}$ & 6.9 & 145 & 0.979 \\
\hline & Granules $630-800 \mu \mathrm{m}$ & 7.1 & 141 & 0.987 \\
\hline & Granules $800-1000 \mu \mathrm{m}$ & 7.3 & 137 & 0.983 \\
\hline \multirow[t]{4}{*}{$50 \% \mathrm{MCC} / 50 \%$ lactose } & Non-roll compacted mixture & 8.1 & 123 & 0.977 \\
\hline & Granules $315-500 \mu \mathrm{m}$ & 7.7 & 130 & 0.971 \\
\hline & Granules $630-800 \mu \mathrm{m}$ & 7.6 & 132 & 0.976 \\
\hline & Granules $800-1000 \mu \mathrm{m}$ & 7.2 & 139 & 0.971 \\
\hline \multirow[t]{4}{*}{$25 \%$ MCC/75\% lactose } & Non-roll compacted mixture & 9.5 & 105 & 0.929 \\
\hline & Granules $315-500 \mu \mathrm{m}$ & 8.4 & 120 & 0.954 \\
\hline & Granules $630-800 \mu \mathrm{m}$ & 8.2 & 122 & 0.984 \\
\hline & Granules $800-1000 \mu \mathrm{m}$ & 8.4 & 119 & 0.968 \\
\hline
\end{tabular}

\section{Results and discussion}

\subsection{Granule size distribution and shape}

Particle size and particle shape may play an important role in the densification process, affecting the interparticulate interaction. In this study, the granules were obtained under similar conditions of roll compaction and milling, therefore only small differences among the particle size distributions for the different compositions were observed (Fig. 3). Three sieve fractions (315-500, 630-800 and 800-1000 $\mu \mathrm{m}$ ) were chosen in order to analyse the effect of the particle size in further evaluation.

In Fig. 4, the SEM pictures of the granules for the three mixtures show that the granules have an irregular shape. In general, an irregular shape and a rough surface, improve the bonds between particles and, therefore, the compactability of tablets. From the pictures, it can be noticed that the higher is the percentage of lactose in the mixture, the smoother the surface becomes (Fig. 4c). Surface roughness has been reported to influence the mechanical behaviour of the excipients and the mechanical properties of the tablet. Brittle materials result in smoother granules and, therefore, smoother compacts with high surface variability due to particle fracture [12].

\subsection{Compressibility}

Results of the Heckel analysis are summarized in Table 2. K represents the Heckel coefficient (slope of the Heckel plot) and its inverse value $\mathrm{P}_{\mathrm{y}}$, represents the yield pressure.

Regarding the composition, the results show that the mixture with a proportion of $25 \% \mathrm{MCC} / 75 \%$ lactose and their granules were more compressible than the other compositions.

Comparing the compressibilities of original feed powder and granules, it was found that feed powders are more compressible than granules, mainly for the proportion $25 \% \mathrm{MCC} / 75 \%$ lactose. Feed powders can be rearranged more easily during compression, resulting in a larger compressibility. On the other hand, roll-compacted granules were (a)

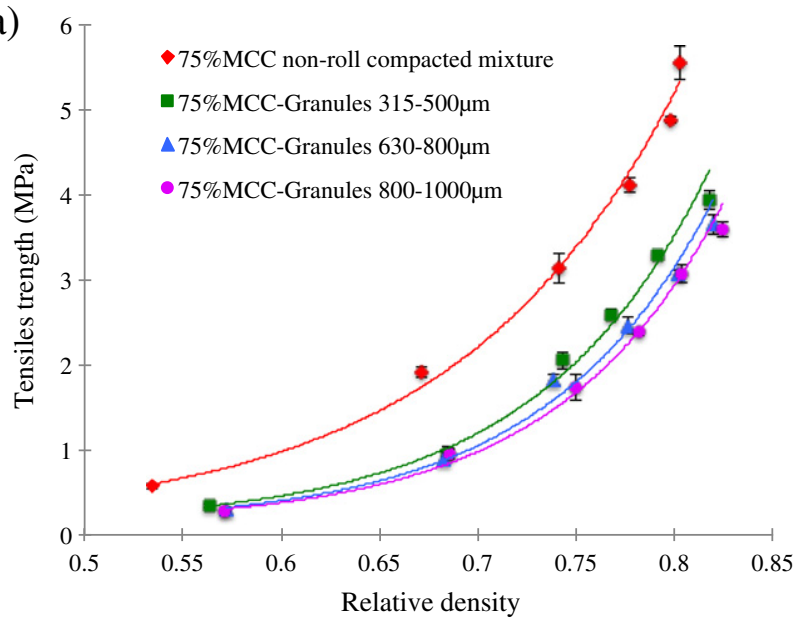

(b)

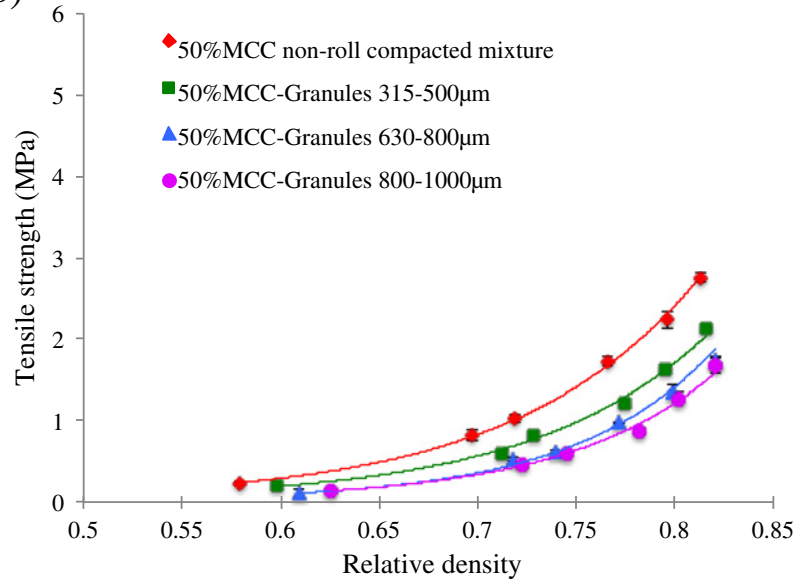

(c)
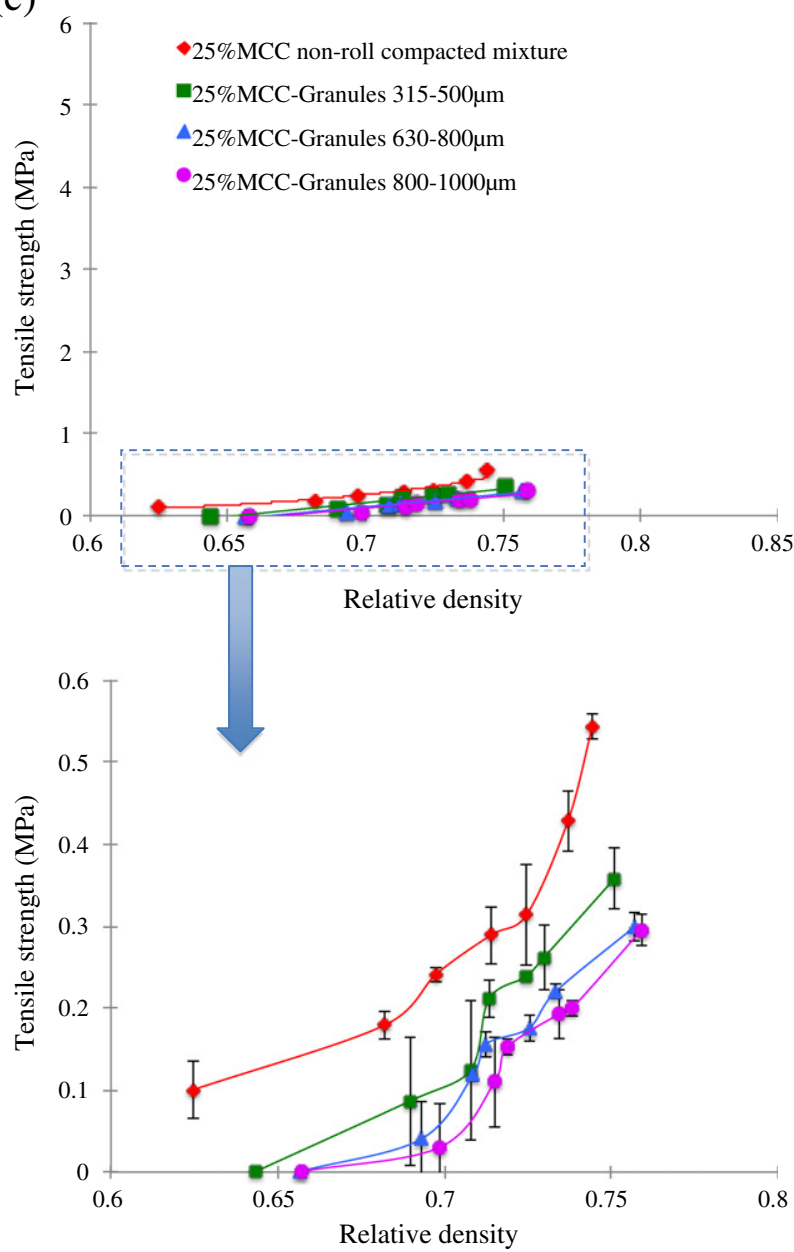

Fig. 5. Tensile strength of tablets as function of relative density (a) $75 \% \mathrm{MCC} / 25 \%$ lactose, (b) $50 \% \mathrm{MCC} / 50 \%$ lactose and (c) $25 \% \mathrm{MCC} / 75 \%$ lactose. 
relatively denser than feed powder, resulting in a lower compressibility. Compressibility can be related to the flowability of powders. Higher compressibility of a powder bed means less flowable powder.

Among the particle sizes, it was not found a pronounced difference in compressibility between granule size fractions. As it was described by Šantl [13], at low pressure granules fragment into smaller particles and when the compression is increased, the extensive fragmentation nullifies the effect of particle size on compressibility.

The yield pressure $\left(\mathrm{P}_{\mathrm{y}}\right)$, which indicates the plasticity of the system, has lower values for a high percentage of lactose and it is lower for the original feed powder than for granules, although the values do not differ significantly from one mixture to another.

\subsection{Tensile strength}

The diametrical crushing load of tablets was measured with a diametric strength tester and the tensile strength of the compacts $\left(\sigma_{t}\right)$ was calculated according to Eq. (5). The tablet tensile strengths as functions of the relative densities are shown in Fig. 5.

Regarding the composition, as ductile materials result into higher tablet tensile strength, the tablets produced with high percentage of MCC have higher tensile strength. On the other hand, a high percentage of lactose in the mixture means lower tensile strength. For brittle material, the compaction decreases the original particle size, reducing the contact surface between particles and hence the reduction of bonding potential between particles. Adding ductile material, the development of large contact surface due to plastification increases the strength of the composite material.

Attending to the effect of roll compaction on the tensile strength, it can be observed that the tablets produced with granules from roll-compacted mixtures show lower tensile strength than the tablets produced with the original binary mixtures. This phenomenon was reported before in the literature [3-7] and it is known as "loss of reworkability". In the case of $75 \%$ of MMC in the mixture, the reduction of tablet strength after roll compaction is more significant than for the others compositions. When a brittle material is incorporated in the formulation, the effect of loss of tabletability is less pronounced at identical compaction conditions, obtaining closer results to those obtained with the original binary mixtures. The granules are an agglomeration of particles and, when the pressure is applied, the granules break into smaller particles, assimilating their behaviour to a brittle material under densification. These results confirm that the effect of size enlargement process by roll compaction can be minimised by incorporating an adequate amount of brittle excipient, as it was reported by [8]. In order to reduce the effect of loss of reworkability, quality by design should be applied in the formulation of the mixture.

The particle size plays also an important role in the final tabletability. An increase in the granule size is translated into a reduction of tensile strength of tablet. The granules with a size of $800-1000 \mu \mathrm{m}$ have the lowest tensile strength, although the differences of tensile strength among the different particle sizes is more pronounced for a high percentage of MCC in the mixture. For materials with a fragmentary behaviour, the particle size is less important than for plastic materials, and therefore, tablet strength is less affected by the particle size.

\subsection{Densification behaviour}

As it could be observed before, roll-compaction process has an effect on the resulting tensile strength of tablets. In order to understand more why this phenomenon takes place, a stress transmission analysis was done.

During the die compaction of a powder bed, the capacity of the mass to convert the applied pressure to the axial and radial densification is an intrinsic characteristic of the behaviour of that powder. An upper force is applied and the stress is transmitted from the top to the bottom of the powder causing its densification in the axial direction whereas a
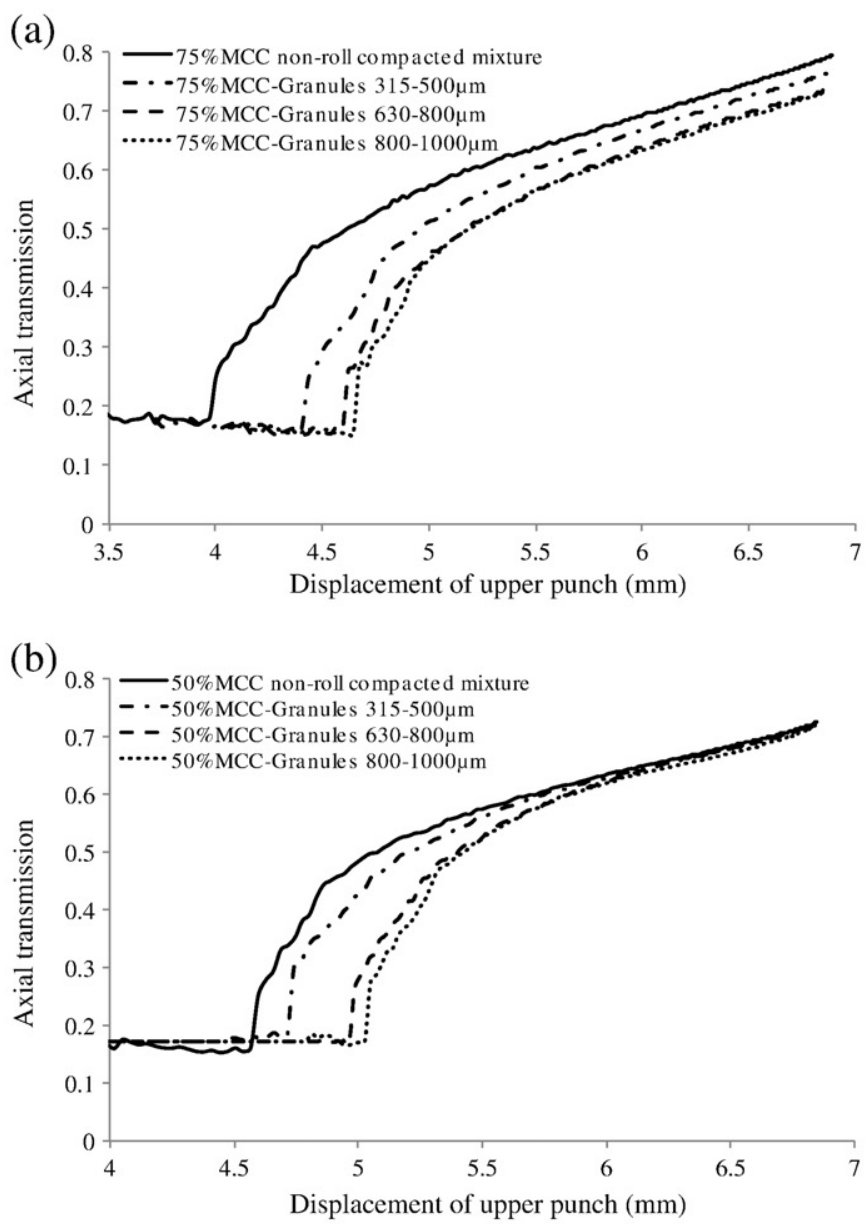

(c)

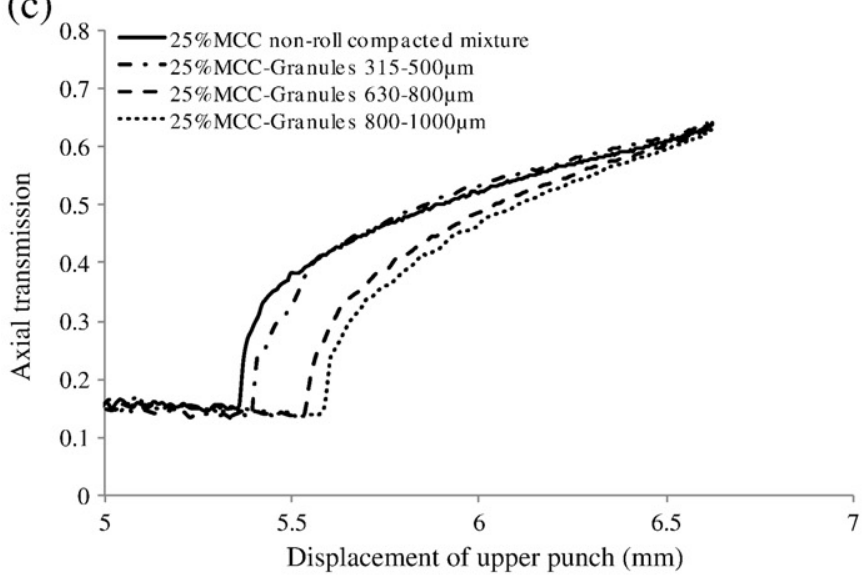

Fig. 6. Axial transmission ( $\operatorname{tr}_{\text {axial }}$ ) for (a) $75 \% \mathrm{MCC} / 25 \%$ lactose, (b) $50 \% \mathrm{MCC} / 50 \%$ lactose and (c) $25 \% \mathrm{MCC} / 75 \%$ lactose.

stress is developed in die cavity by expansion in normal direction to the die wall and the densification in the radial direction takes place [9].

The behaviour of the binary mixtures and their granules during die compaction was analysed through the axial and radial stress transmissions (Eqs. (1) and (2)). Fig. 6 shows the displacement of the upper punch versus the axial transmission, defined as the ratio of pressure transmitted from the top to the bottom of the powder bed. It can be observed that, at the beginning of the compaction cycle, the axial transmission is very low for the three compositions. Less than $20 \%$ of the applied pressure is transmitted to the bottom of the powder bed, for the three binary mixtures and their granules. After a certain pressure, 
Table 3

Densification behaviour: maximum displacement, applied upper pressure at maximum displacement and radial stress transmission at maximum displacement.

\begin{tabular}{|c|c|c|c|c|}
\hline Mixture & & $\begin{array}{l}\text { Maximum displacement } \\
\text { of upper punch, } \mathrm{d}_{\max }(\mathrm{mm})\end{array}$ & $\begin{array}{l}\text { Maximum applied pressure } \\
\text { at } \mathrm{d}_{\max }, \sigma_{\mathrm{u}, \max }(\mathrm{MPa})\end{array}$ & $\begin{array}{l}\text { Radial Stress transmission } \\
\left(\operatorname{tr}_{\text {radial }}\right) \text { at } \sigma_{\mathrm{u}, \text { max }}\end{array}$ \\
\hline \multirow[t]{4}{*}{$75 \% \mathrm{MCC} / 25 \%$ lactose } & Non-roll compacted mixture & $6.890 \pm 0.006$ & $74.341 \pm 2.838$ & $0.265 \pm 0.005$ \\
\hline & Granules $315-500 \mu \mathrm{m}$ & $6.875 \pm 0.003$ & $79.717 \pm 1.143$ & $0.270 \pm 0.003$ \\
\hline & Granules $630-800 \mu \mathrm{m}$ & $6.870 \pm 0.002$ & $80.770 \pm 0.801$ & $0.271 \pm 0.004$ \\
\hline & Granules $800-1000 \mu \mathrm{m}$ & $6.861 \pm 0.003$ & $80.607 \pm 0.947$ & $0.266 \pm 0.015$ \\
\hline \multirow[t]{4}{*}{$50 \% \mathrm{MCC} / 50 \%$ lactose } & Non-roll compacted mixture & $6.853 \pm 0.004$ & $83.491 \pm 0.724$ & $0.283 \pm 0.007$ \\
\hline & Granules $315-500 \mu \mathrm{m}$ & $6.851 \pm 0.003$ & $85.536 \pm 0.398$ & $0.286 \pm 0.002$ \\
\hline & Granules $630-800 \mu \mathrm{m}$ & $6.842 \pm 0.003$ & $87.199 \pm 0.832$ & $0.272 \pm 0.004$ \\
\hline & Granules $800-1000 \mu \mathrm{m}$ & $6.845 \pm 0.003$ & $88.191 \pm 0.922$ & $0.272 \pm 0.004$ \\
\hline \multirow[t]{4}{*}{$25 \% \mathrm{MCC} / 75 \%$ lactose } & Non-roll compacted mixture & $6.596 \pm 0.056$ & $48.223 \pm 3.573$ & $0.330 \pm 0.004$ \\
\hline & Granules $315-500 \mu \mathrm{m}$ & $6.627 \pm 0.012$ & $47.409 \pm 3.647$ & $0.337 \pm 0.011$ \\
\hline & Granules $630-800 \mu \mathrm{m}$ & $6.624 \pm 0.014$ & $47.081 \pm 3.032$ & $0.338 \pm 0.009$ \\
\hline & Granules $800-1000 \mu \mathrm{m}$ & $6.629 \pm 0.012$ & $44.121 \pm 5.384$ & $0.351 \pm 0.019$ \\
\hline
\end{tabular}

the axial transmission starts to increase reaching at the maximum pressure a value that varies from 60 to $80 \%$ of transmission depending on the composition and granule size.

It was noticed that for a specific applied pressure, less pressure is transmitted for the granules than for the original feed powder. Regarding the particle size, transmission has also lower values when the granule size is increased. Due to their fragmentary behaviour, the granules consume part of the applied pressure in an intermediate densification step that consists on the breakage into smaller particles and the rearrangement of these new particles. Hence, in the densification of granules, less energy is consumed to form inter-particulate bonds, which can explain the reduction of their tablet tensile strength.

The stress on the wall of the die was also measured and the radial transmission ratio was calculated according to Eq. (2).

During the compaction cycle, the radial stress resulted independent from the granule size, obtaining the same values for feed powders than for granules of different sizes for a certain composition. These results at maximum pressure are listed in Table 3.

However, it could be noticed that the radial stress ratio increases slightly according to the increase of lactose proportion in the mixture. Indeed, lactose is considered as a cohesive powder, particle-particle and particle-surface, and lubrication is commonly used for the compaction of this excipient.

The results from the densification behaviour analysis show heterogeneity of the stress distributions in the tablets. This leads to heterogeneity of the density distribution, which affects the mechanical resistance of the compacts.

\section{Conclusion}

The objective of this work was to evaluate the effect of roll compaction on binary mixtures of two excipients with different mechanical behaviour. The phenomenon of "loss of re-workability" after roll compaction is translated into a reduced tablet tensile strength. In this study, it was confirmed that tablets produced with granules from rollcompacted mixtures show lower tensile strength than the tablets produced with the original binary mixtures. However, the reduction of tensile strength is more relevant for a high percentage of ductile material in the mixture. Attending the granule size, an increase in the size leads to a reduction of tensile strength of tablet. These results confirm that incorporating an adequate amount of brittle excipient and controlling the granule size, the effect of size enlargement process by roll compaction can be minimised. Quality by design should be applied in the formulation and parameters to predict the optimal final properties.

In order to better understand the loss of reworkability, an analytical technique based on the stress transmission analysis was proposed and applied to the densification behaviour of binary mixtures and granules. It was shown that the transmission stress in axial direction differs depending on the powder behaviour. Due to their fragmenting behaviour under pressure, roll compacted granules work against the axial transmission. Indeed, a part of the applied pressure is consumed in the breakage of granules into smaller particles, improving the volume reduction but reducing the available energy to form strong interparticulate bonding. This is typically the densification mechanism of brittle materials and that is why brittle excipients are less sensitive to the effect of loss or re-workability after roll compaction. On the other hand, the radial transmission was slightly affected by the increase of lactose in the mixture and it resulted indifferent to the increase of granule size.

\section{Acknowledgement}

This project has received funding from the European Union's Seventh Framework Programme for research, technological development and demonstration under grant agreement no. 316555.

\section{References}

[1] P. Kleinebudde, Roll compaction/dry granulation: pharmaceutical applications, Eur. J. Pharm. Biopharm. 58 (2004) 317-326.

[2] S. Malkowska, K.A. Khan, Effect of recompression on the properties of tablets prepared by dry granulation, Drug Dev. Ind. Pharm. 9 (1983) 331-347.

[3] M. Šantl, M.I. Ilić, F. Vrečer, S. Baumgartner, A compressibility and compactibility study of real tableting mixtures: the impact of wet and dry granulation versus a direct tableting mixture, Int. J. Pharm. 414 (2011) 131-139.

[4] M.G. Herting, P. Kleinebudde, Studies on the reduction of tensile strength of tablets after roll compaction/dry granulation, Eur. J. Pharm. Biopharm. 70 (2008) 372-379.

[5] C. Bacher, P.M. Olsen, P. Bertelsen, J.M. Sonnergaard, Compressibility and compactibility of granules produced by wet and dry granulation, Int. J. Pharm. 358 (2008) 69-74.

[6] M.G. Herting, P. Kleinebudde, Roll compaction/dry granulation: effect of raw material particle size on granule and tablet properties, Int. J. Pharm. 338 (2007) 110-118.

[7] C. Sun, M.W. Himmelspach, Reduced tabletability of roller compacted granules as a result of granule size enlargement, J. Pharm. Sci. 95 (2006) 200-206.

[8] S.J. Wu, C. Sun, Insensitivity of compaction properties of brittle granules to size enlargement by roller compaction, J. Pharm. Sci. 96 (2007) 1445-1450.

[9] A. Michrafy, H. Diarra, J. Dodds, Compaction behavior of binary mixtures, Powder Technol. 190 (2009) 146-151.

[10] R.W. Heckel, Density-pressure relationship in powder compaction, Trans. Metall. Soc. AIME 221 (1961) 671-675.

[11] J.T. Fell, J.M. Newton, Determination of tablet strength by the diametral-compression test, J. Pharm. Sci. 59 (1970) 688-691.

[12] P. Narayan, B.C. Hancock, The relationship between the particle properties, mechanical behavior, and surface roughness of some pharmaceutical excipient compacts, Mater. Sci. Eng. 355 (2003) 24-36.

[13] M. Šantl, I. Ilić, F. Vrečer, S. Baumgartner, A compressibility and compactibility study of real tableting mixtures: the effect of granule particle size, Acta Pharma. 62 (2012) 325-340. 